\title{
Research on comprehensive evaluation of city community safety capability based on factor analysis \\ - Taking Tangshan City as an example
}

\author{
Li Zhixin \\ College of Management and \\ Economics \\ Tianjin University, \\ Tianjin, China \\ e-mail: qalizhixin@163.com
}

\author{
Zhang Lihua \\ College of Economics \\ Hebei United University \\ Tangshan, China \\ e-mail: 80304144@qq.com
}

\author{
LI Wenli \\ Party committee \\ Tangshan City Party School of the \\ C.P \\ Tangshan, China \\ e-mail: tshdxlwl1966@sina.com
}

\begin{abstract}
The purpose of this research is to comprehensively evaluate community safety capacity building of Tangshan City through extensive research, to provide basis for the future safety construction of the city. In the research, we put forward the index system of comprehensive assessment of city community safety capability, based on extensive expert investigation and questionnaire investigation, using factor analysis method, extract 4 city community safety factors, and on the basis of this, the paper evaluates the safety capacity construction situation of Tangshan City's six area, the method can also provide reference for other city's safety capability evaluation.
\end{abstract}

Keywords-Factor analysis; safety capability; comprehensive evaluation

\section{INTRODUCTION}

Community is common unit composed of people live in a certain area, it is the basic unit of the society. Regional and common sense, a sense of belonging of members are the two basic characteristics of community. A small residential area, a city district, or a city, all can be understood as a community. According to statistics, by the end of 2010, the number of China's city has reached 657, along with the further acceleration of the process of urbanization, number and scale of city will be increased: while big city grows rapidly, a number of small and medium-sized city will develop rapidly, under this situation, the number of city community will be increased. In this paper, we will study the six districts of Tangshan City, taking the city district as a community.

Along with the demand for security is higher and higher, objectively require city management to strengthen safety management. While some of the community have been developing safety community construction, to conduct a comprehensive, integrated assessment for community safety status in different areas of the city, will help the government to have a comprehensive grasp of the city's safety situation, to identify vulnerability and threat of the city, this will greatly contribute to comprehensively grasp and control the safety related systems and the existing measures objectively. Therefore, it is necessary to carry out safety capability assessment of city community.

\section{THE ESTABLISHMENT OF COMMUNITY SAFETY} CAPABILITY COMPREHENSIVE EVALUATION INDEX SYSTEM

The scientific selection of comprehensive evaluation index of community security capability is the basis and prerequisite for accurate evaluation of community safety capability, in this paper, the index selection will follow the following principles: the comprehensive principle, the systematic principle, the guiding principle, and the operating principle. On the basis of the above mentioned principles, we divide community safety capacity into the following 13 indexes, refer to Table I. Each index includes two or more sub-indexes.

It can be seen from the Table I, the index basically includes the main factors to reflect the community security capabilities with good illustrative, among the variables, X1 represents the safety management capability, X2-X3 represents the technical support capability, X4-X5 represents the rescue aid assessment capability, $\mathrm{X} 6-\mathrm{X} 7$ denotes the project defense capability, X8-X10 represents resource supply capability, X11-X13 represents safety cultural situation, all indicators are qualitative index, the index value of data was obtained through questionnaire survey calculation, the capability situation of evaluation subject in the questionnaire can be scaled from " very poor " to " good ", which are represented by the 1-10 score.

\section{TABLE I. THE COMMUNITY SAFETY CAPABILITY EVALUATION INDEX SYSTEM}

\begin{tabular}{|l|l|}
\hline \multicolumn{1}{|c|}{ Variables } & \multicolumn{1}{c|}{ Index } \\
\hline X1 & Construction of safety management mechanism \\
\hline X2 & Monitoring and early warning of natural factors \\
\hline X3 & Human factors monitoring and early warning \\
\hline X4 & Rescue capability \\
\hline X5 & External assistance and aid \\
\hline X6 & Engineering facilities and building resilience \\
\hline X7 & Shelter construction and use \\
\hline X8 & The money invested in the construction of safety \\
\hline X9 & Security Reserve \\
\hline X10 & Emergency resource use \\
\hline
\end{tabular}




\begin{tabular}{|l|l|} 
X11 & Safety concept \\
\hline X12 & Safety knowledge \\
\hline X13 & Safety behavior \\
\hline
\end{tabular}

\section{EMPIRICAL ANALYSIS}

\section{A. Sample data acquisition}

The samples are from six areas in Tangshan City, Hebei Province, which are Road North district, Road South district, Kaiping District, Guye District, Fengrun District and Fengnan District, they will be represented by district 1-6 in this paper. In the design of the questionnaires, we first carry out in-depth interviews with experts on city community security, studied the related literatures, on the basis of these, we established the index system. In the design of the questionnaires, we made our efforts to avoid unclear character expression, and loopholes of unreasonable indicators, and made a detailed explanation on some indexes in the questionnaires. In order to better reflect the actual situation of the safety construction of Tangshan's central district, the survey questionnaires were handed out to four levels, which are the municipal departments, district departments, community management and community residents, a total of 138 questionnaires were issued, excluding 8 invalid questionnaires, there were130 effective questionnaires, the effective recovery rate reached $94.2 \%$, met the need of social survey requirements.

The above mentioned indexes reflected community security capacity from different angles, and there is a certain correlation between the index, in order to reflect the community safety capability and community feature, illustrate the strengths and weaknesses of each aspect, there should be a comprehensive evaluation function and evaluation indexes which reflect community characteristic. We considered construct the comprehensive evaluation function by using the principal component analysis method. The advantage of it is that it determines the weight coefficient on the basis of inner relationship between the indexes, which were analyzed based on the data, not affected by subjective factors, which was helpful to the analysis and evaluation. We use factor analysis to find the inner relationship of data, concentrated many indexes into a few factors, and then combined with the factor loading matrix to determine the weight of each index of community safety capabilitiy, and finally calculate the comprehensive score of community safety capability.

\section{B. Feasibility of data inspection}

A premise of factor analysis is: there is correlation between the original data selected, so before we solve the initial factor, need test whether data is suitable. Statistic value of KMO ( Kaiser-Meyer-Olkin ) test is used to compare variables between the simple correlation and partial correlation coefficient. Numerical variation of KMO test changes from 0 to 1 , in general, if KMO value is more close to 1 , it is more suitable for factor analysis, if it is too small, indicates that the correlation can't be explained by other variables, thus factor analysis is not suitable. If the value of
KMO is 0.7, means " good", 0.6 means " moderate ", 0.5 means " bad " for analysis[2]. In this study, the value is approximately 0.8 , indicating that factor analysis can be used.

The purpose of Bartlett test is to determine whether the required data is taken from the general multivariate normal distribution, if the difference test value $\mathrm{F}$ is significant, indicates that request data are from normal distribution, we can do further analysis. From the results of this study, the concomitant probability values in this example is 0.0000 , the significance level is less than the specified 0.05 , to reject the null hypothesis, the correlation coefficient matrix is not the unit matrix, there was a correlation between the original variables, it is suitable for factor analysis.

TABLE II. VALUE OF KMO OF SAMPLE ADEQUACY MEASUREMENT AND THE BARTLETT TEST OF SPHERICITY

\begin{tabular}{|l|l|l|}
\hline $\begin{array}{c}\text { Kaiser-Meyer-Olkin } \\
\text { sample measurement }\end{array}$ & $\begin{array}{c}\text { Bartlett' test } \\
\text { of sphericity }\end{array}$ & Significance \\
\hline 0.825 & 214.540 & 0.0000 \\
\hline
\end{tabular}

\section{Identify main factor}

By using SPSS software, we could calculate eigenvalues, the contribution rate and the cumulative contribution rate, there are strong relationships between variables and factors, the factors can reflect the information of sample index, effect of factor analysis is significant.

TABLE III. THE CUMULATIVE CONTRIBUTION RATE OF VARIANCE

\begin{tabular}{|l|l|l|l|l|l|}
\hline \multicolumn{3}{|c|}{ Initial eigenvalue } & \multicolumn{3}{|c|}{$\begin{array}{c}\text { Extraction of square total and } \\
\text { load }\end{array}$} \\
\hline eigenvalue & $\begin{array}{c}\text { cumulati } \\
\text { contributio } \\
\text { n rate\% } \\
\text { contribut } \\
\text { ion } \\
\text { rate.\% }\end{array}$ & $\begin{array}{c}\text { eigenvalu } \\
\text { e }\end{array}$ & $\begin{array}{c}\text { contribut } \\
\text { ion } \\
\text { rate \% } \\
\text { ve } \\
\text { contribut } \\
\text { ion rate. } \\
\%\end{array}$ \\
\hline 5.423 & 41.717 & 41.717 & 5.423 & 41.717 & 41.717 \\
\hline 4.519 & 34.759 & 76.476 & 4.519 & 34.759 & 76.476 \\
\hline 1.709 & 13.146 & 89.622 & 1.709 & 13.146 & 89.622 \\
\hline 1.133 & 8.719 & 98.341 & 1.133 & 8.719 & 98.341 \\
\hline .216 & 1.659 & 100.000 & & & \\
\hline $3.025 \mathrm{E}-16$ & $2.327 \mathrm{E}-15$ & 100.000 & & & \\
\hline $1.746 \mathrm{E}-16$ & $1.343 \mathrm{E}-15$ & 100.000 & & & \\
\hline $8.054 \mathrm{E}-17$ & $6.196 \mathrm{E}-16$ & 100.000 & & & \\
\hline $3.513 \mathrm{E}-17$ & $2.703 \mathrm{E}-16$ & 100.000 & & & \\
\hline $1.431 \mathrm{E}-17$ & $1.101 \mathrm{E}-16$ & 100.000 & & & \\
\hline$-1.611 \mathrm{E}-16$ & $-1.240 \mathrm{E}-15$ & 100.000 & & & \\
\hline$-1.841 \mathrm{E}-16$ & $-1.416 \mathrm{E}-15$ & 100.000 & & & \\
\hline$-2.916 \mathrm{E}-16$ & $-2.243 \mathrm{E}-15$ & 100.000 & & & \\
\hline
\end{tabular}

In determining the factor number, we can accord to the eigenvalue ( Table III) and scree plot(Figure 1) to select the factors whose eigenvalue is greater than 1 on the basis of the principal component analysis, and in accordance with the principle of factor analysis, principal factor selected could accumulatively explain a total of more than $85.85 \%$ of the variance. The results show, the characteristic values of the fore 4 factors of the correlation matrix are more than 1 , they 
accumulatively explain a total of $98.341 \%$ of the variance, as in Table III, meet the conditions set, so we selected 4 common factors.

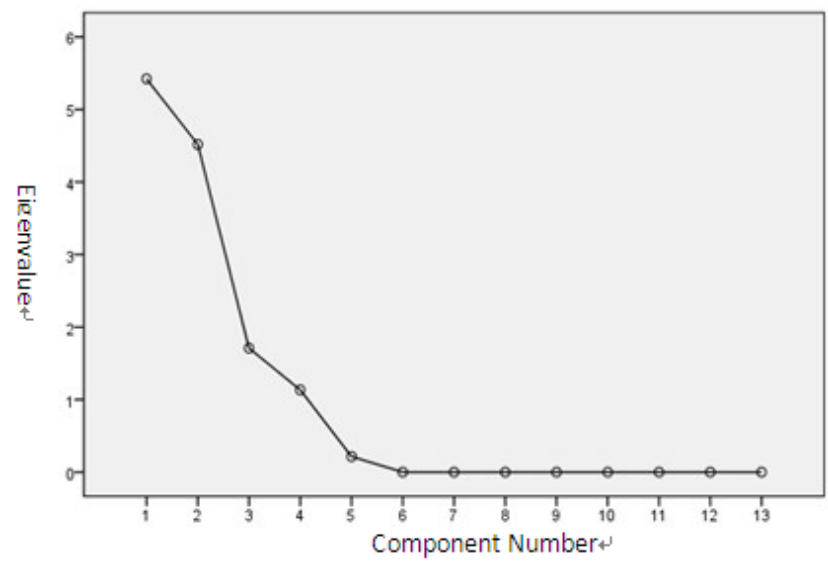

Figure 1. scree plot

D. using $R$ mode factor analysis to calculate the weight of each indicator

$\mathrm{R}$-mode factor analysis is a multivariate relationships analysis method between indexes in a study of mathematical statistics. First, we test the obtained data, calculate correlation coefficient matrix of each two indexes on the computer, then through the matrix transformation, to calculate eigenvalue $\lambda_{i}$ and eigenvalue vector $\mu_{i j}$, on the basis of $\lambda_{i}$, we can select several main factors, we can use the several main factors to reflect the most information of the original indexes, and then according to the formula:

$$
a_{i j}=\mu_{i j} / \sqrt{\lambda_{i}}
$$

We can calculate the initial factor matrix. Because the factor loading $a_{i j}$ is the correlation coefficient of index $i$ and the main component $\mathrm{j}$ in the initial factor matrix, which can determine the relative importance of each index according to the factor loading of each index size, so as to calculate the index of "weight " [3] . This paper calculates 4 main factors using SPSS17.0 software ( see Table III and figure 1 ), factor matrix calculated as in Table IV.

TABLE IV. FACTOR lOADING MATRIX

\begin{tabular}{|l|l|l|l|l|}
\hline & \multicolumn{5}{|c|}{ Principal factors } \\
\hline \multicolumn{1}{|c|}{ Safety capability indicator } & F1 & F2 & F3 & F4 \\
\hline $\begin{array}{l}\text { Construction of safety management } \\
\text { mechanism (X1) }\end{array}$ & .906 & -.222 & .348 & .091 \\
\hline $\begin{array}{l}\text { Monitoring and early warning of } \\
\text { natural factors (X2) }\end{array}$ & .366 & .911 & -.030 & -.134 \\
\hline $\begin{array}{l}\text { Human factors monitoring and early } \\
\text { warning (X3) }\end{array}$ & .842 & .204 & -.358 & -.293 \\
\hline Rescue capability (X4) & .720 & -.660 & .146 & -.060 \\
\hline External assistance and aid (X5) & .885 & .462 & -.004 & .020 \\
\hline
\end{tabular}

\begin{tabular}{|l|l|l|l|l|}
\hline $\begin{array}{l}\text { Engineering facilities and building } \\
\text { resilience (X6) }\end{array}$ & .121 & .958 & -.098 & -.166 \\
\hline Shelter construction and use (X7) & .734 & .245 & .267 & .549 \\
\hline $\begin{array}{l}\text { The money invested in the } \\
\text { construction of safety (X8) }\end{array}$ & .595 & -.772 & -.163 & -.082 \\
\hline Security Reserve (X9) & .774 & -.439 & -.067 & -.451 \\
\hline Emergency resource use (X10) & .826 & .215 & .471 & .124 \\
\hline Safety concept (X11) & .299 & .062 & -.686 & .660 \\
\hline Safety knowledge (X12) & .316 & .823 & -.435 & -.166 \\
\hline Safety behavior (X13) & -.281 & .674 & .666 & -.023 \\
\hline Extraction method: principal component analysis \\
\hline
\end{tabular}

The initial factor $f_{i j}$ reflects the correlation degree of each index and the main factor (absolute value represents relate degree). The total of the absolute value of the 13 initial factor in first factor(F1) is 7.665, then weight of X1 on the first main factor is $0.906 / 7.665=0.118$, weight on the second main factors is 0.042 , the weight on third main factors is 0.103 , the weight on fourth main factors is 0.032 , hence the weight coefficient of the first index is:

$\mathrm{T} 1=0.118+0.042+0.103+0.032=0.295$

In the same way we can calculate the following results: $\mathrm{T} 2=0.275, \mathrm{~T} 3=0.358, \mathrm{~T} 4=0.035, \mathrm{~T} 5=0.210, \mathrm{~T} 6=0.284$, $\mathrm{T} 7=0.416, \mathrm{~T} 8=0.300, \mathrm{~T} 9=0.363, \mathrm{~T} 10=0.332, \mathrm{~T} 11=0.488$, $\mathrm{T} 12=0.383, \mathrm{~T} 13=0.368$, through normalization processing of the above data, we can determine the weight coefficient of the 13 indicators: $0.072,0.067,0.087,0.008,0.051,0.069$, 0.101, 0.073, 0.088, 0.081, 0.119, 0.093, 0.090.

\section{E. Calculation of the comprehensive safety capability score of each community}

Using the above mentioned weight in 3.3, and indexes of the six communities, calculate on the basis of weighting comprehensive evaluation method, the comprehensive scores of community safety capability can be obtained, the results are in Table V.

TABLE V. THE COMMUNITY SAFETY COMPREHENSIVE SCORE

\begin{tabular}{|l|l|l|l|l|l|l|}
\hline community & \multicolumn{1}{|c|}{ No.1 } & No.2 & No.3 & \multicolumn{1}{|c|}{ No.4 } & No.5 & \multicolumn{1}{c|}{ No.6 } \\
\hline Score & 8.160 & 8.055 & 7.869 & 8.158 & 7.769 & 7.794 \\
\hline Ranking & 1 & 3 & 4 & 2 & 6 & 5 \\
\hline
\end{tabular}

\section{CONCLUSION}

Among the six District of Tangshan City, community No.1 and community No.2 are central region of Tangshan City in history, security construction base is fair good. Especially the community No.1, it is the city's political, economic, and cultural center, the average level of education of the residents is the highest among the six districts. In recent years, various departments and units attached great importance on safety construction, safety construction effect is obvious, so in the evaluation of community security ability, it acquires the highest comprehensive score.

Community No. 4 is the old coal mining district in Tangshan, In the years before 2009, because of system reason, as well as the economy downturn with the depletion of coal resources, public order was also poor, it's safety 
environment remain poor for many years, security situation was not optimistic. But since 2009, the new district government made great efforts in changing the image if the area, it invested huge sums of money on safety construction, the safety construction level has been greatly raised, in some areas of safety construction, it even walks in the forefront of Hebei Province. But safety capability construction need long time accumulation, so, comprehensively evaluation, it is still slightly inferior to community No.1.

As for the community No.3, No.5 and No.6, they have jurisdiction over large rural areas and rural population, for example, urban population in the community No. 5 only accounts for $41.8 \%$. The urbanization rate of these three district is relatatively high than the rest rural areas, but there is still obvious distance in terms of safe community construction compared with the community No.1,No.2 andNo.4, there is still a long way to go in the safety capability construction.

\section{ACKNOWLEDGMENT}

R.B.G. thanks Tangshan City science and Technology Bureau. This paper is one of the results of "Study of the management mode innovation of Tangshan city safety community construction and countermeasures" (Project umber: 12140201B-1 ) .

\section{REFERENCES}

[1] Xinhuanet, The number of cyty in China has reached 657, http://news.xinhuanet.com/local/2011-06/16/c_121545801.htm

[2] Liu Lei, Li Nan, "The application of factor analysis method to evaluate the construction project dynamic alliance partner," in Mathematical statistics and management, Vol.27. 2008, pp.893-894.

[3] Wang Lude, “ By using R analysis the factor evaluation weight,” in Sports statistics, vol.1. 1991, pp 66-67

[4] Xue Wei, “statistical analysis and SPSS application,”Bei Jing: renmin university of China press, 2001

[5] Zhang Jing, Ai Bin, Xu Jian Hua,“A Study on Evaluation of Ecological Community Based on Principal Component Analysis Method__ A case study within outer ring road of Shanghai city,"in Ecologic science,Vol.24,2005,pp. 339-343 